\title{
Evidence-based psycho-oncology: A priority in mental health
}

\author{
Oscar Galindo-Vázquez, ${ }^{\prime}$ Rosario Costas-Muñiz²
}

Servicio de Psicooncología, Unidad de Investigación y Desarrollo de la Psicooncología, Instituto $\mathrm{Na}^{-}$ cional de Cancerología INCan, Ciudad de México, México.

2 Memorial Sloan-Kettering Cancer Center, Department of Psychiatry \& Behavioral Sciences. Immigrant Health \& Cancer Disparities.

\section{Correspondence:}

Oscar Galindo Vázquez

Servicio de Psicooncología, Unidad de Investigación y desarrollo de la Psicooncología, Instituto Nacional de Cancerología INCan.

Avenida San Fernando 22, Colonia Sección XVI, C.P. 14080, Ciudad de México, México.

Phone: +52 (55) 5628 - 0400, ext. 60259 y 12059

Email: psigalindo@yahoo.com.mx

Citation:

Galindo-Vázquez, $\bigcirc$ \& Costas-Muñiz, R. (2019). Evidence-based psycho-oncology: A priority in mental health. Salud Mental, 42(3), 101-102.

DOI: $10.17711 /$ SM.0185-3325.2019.013
Comprehensive cancer care includes psycho-oncological treatment. The reliable identification of emotional distress is a prerequisite for adequate psycho-oncological treatment (Senf, Fettel, Demmerle, \& Maiwurm, 2019). This derives from the prevalence of mental health problems among the population with cancer. For example, depression has been reported between $8 \%$ and $24 \%$ (Krebber, Buffart, Kleijn, Riepma et al., 2014), which can be increased and accompanied by clinical conditions such as the demoralization syndrome and existential distress in patients with advanced cancer (An, Lo, Hales, Zimmermann et al., 2018). It can also impact patients' quality of life (Aguado Loi, Baldwin, McDermott, McMillan et al., 2013; Yanez, Thompson, \& Stanton, 2011), adherence to treatment (Costas-Muniz, Leng, Diamond, Aragones et al., 2015), increasing the days of hospitalization, and communication issues with the health team (Krok-Schoen, Fernandez, Unzeitig, Rubio et al., 2019).

In recent years, the field of psycho-oncology has seen the development of clinical practice guidelines for cancer care in several countries (Holland, Watson, \& Dunn, 2011). The guidelines proposed by the National Comprehensive Cancer Network (NCCN) and the Institute of Medicine (IOM) identify four key components of the process that constitute the best practices: detection, evaluation, treatment, and follow-up. The guidelines indicate that health professionals should participate in each stage. For example, distress has been proposed as the $6^{\text {th }}$ vital sign and greater efforts have been made to recognize the psychosocial aspects of the cancer experience (Bultz, 2002).

In this context, an important recommendation stated on the guidelines has been to insist that all patients who initiate treatment should be assessed to determine their psychosocial needs and their level of emotional distress, followed by referral to appropriate resources. However, it is clear that establishing guidelines on its own is not enough to shift attention. To implement recommendations at a clinical level, we must overcome several barriers to psychosocial care (Holland et al., 2011). Even more so when the rise of cancer and survival rates, in the context of severe resource limitations, force us to reconsider the administration of psychosocial care in this population (Fielding, 2019).

The consequences of these limitations are reflected in the fact that psycho-oncology programs are insufficient to meet patients' needs and hard to access outside big cities. Innovative care models are required to close this gap (Vaccaro, Shaw, Sethi, Kirsten et al., 2019). For example, in Mexico, there is a clinical practice guideline for the evaluation and psycho-oncological interventions for adults with cancer in the third level of attention (IMSS, 2017). This guideline gives recommendations based on the best available evidence with the intention of standardizing national care for cancer patients in the third level of care on:

1. The identification of patients with clinical criteria of psycho-oncological alterations;

2. Suggesting the most effective psycho-oncological treatments for patient care, and

3. Establishing the criteria for referral in patients with a history of cancer and psychological disorders.

There are several advantages to treat the psychosocial needs of this group of patients and their informal primary caregivers. By reducing the emotional burden of cancer care, 
we can also reduce its financial burden. Placing the needs of patients directly at the center of the health care model implies a fundamental change in the focus of patient care. This is vital in order for a health system in oncology to be well managed and compassionate with an ethical, emotional, and economic sense (Bultz, 2002). It is clear that psychosocial oncology has grown in the last decade. The publication of reports, guidelines, recommendations, and psychosocial oncology care standards have improved the implementation of activities, services, and psychosocial programs (Grassi \& Watson., 2012). Nevertheless, we still face a challenge in mental health in evidence-based practice.

With the magnitude of evidence-based interventions, the discipline of psycho-oncology has been strengthened and we can administer a large number of evidence-based interventions such as those cataloged on the website of the Instituto Nacional de Cancerología (https://rtips.cancer. gov/rtips/index.do).

However, the vast majority of these evidence-based interventions have been developed and studied in clinical trials with English-speaking samples (Luckett, Goldstein, Butow, Gebski et al., 2011; Yanez et al., 2011). A minority of psycho-oncological interventions has been developed and/ or adapted for Latin and/or Mexican cancer patients (Ashing \& Rosales, 2014; Badger, Segrin, Hepworth, Pasvogel et al., 2013; Dwight-Johnson, Ell, \& Lee, 2005; Penedo, Traeger, Dahn, Molton et al., 2007). Therefore, the need to conduct rigorous studies to adapt and study the efficacy of evidence-based interventions in Mexican populations is imperative. Culturally adapted interventions are much more effective than non-adapted interventions implemented in a new cultural group (Benish, Quintana, \& Wampold, 2011; Griner \& Smith, 2006).

Isn't it time for mental health professionals to take psycho-oncological care as an essential component in caring for their cancer patients? Otherwise, we would return to decades ago when the WHO motto "without mental health there is no health" would not be valid.

Ensuring that psychosocial care services are evidence-based for the Mexican population, that they apply to our context, and are based on the best practices stated in clinical practice guidelines (Holland et al., 2011) will lead to more rigorous work on clinical practice and research from psychologists and psychiatrists to cancer patients and informal primary caregivers, even more so in the Latin American population where the mental health needs of the oncological patient remain a priority yet to be addressed.

\section{REFERENCES}

Aguado Loi, C. X., Baldwin, J. A., McDermott, R. J., McMillan, S., Martinez Tyson, D., Yampolskaya, S., \& Vandeweerd, C. (2013). Risk factors associated with increased depressive symptoms among Latinas diagnosed with breast cancer within 5 years of survivorship. Psycho-Oncology, 22(12), 2779-2788. doi: 10.1002/pon. 3357
An, E., Lo, C., Hales, S., Zimmermann, C., \& Rodin, G. (2018). Demoralization and death anxiety in advanced cancer. Psycho-oncology, 27(11), 2566-2572. doi: 10.1002/pon.4843

Ashing, K. \& Rosales, M. (2014). A telephonic-based trial to reduce depressive symptoms among Latina breast cancer survivors. Psycho-Oncology, 23(5), 507515. doi: 10.1002/pon.3441

Badger, T. A., Segrin, C., Hepworth, J. T., Pasvogel, A., Weihs, K., \& Lopez, A. M. (2013). Telephone-delivered health education and interpersonal counseling improve quality of life for Latinas with breast cancer and their supportive partners. Psycho-Oncology, 22(5):1035-1042. doi: 10.1002/pon.3101

Benish, S. G., Quintana, S., \& Wampold, B. E. (2011). Culturally adapted psychotherapy and the legitimacy of myth: A direct-comparison meta-analysis. Journal of Counseling Psychology, 58(3), 279-289. doi: 10.1037/a0023626

Bultz, B. D. (2002). Changing the face of cancer care for patients, community and the health care system: A report to the government of Canada. Commission on the Future of Health Care in Canada.

Costas-Muniz, R., Leng, J., Diamond, L., Aragones, A., Ramirez, J., \& Gany, F. (2015). Psychosocial correlates of appointment keeping in immigrant cancer patients. Journal of Psychosocial Oncology, 33(2), 107-123. doi: 10.1080/07347332.2014.992084

Dwight-Johnson, M., Ell, K., \& Lee, P. J. (2005). Can collaborative care address the needs of low-income Latinas with comorbid depression and cancer? Results from a randomized pilot study. Psychosomatics, 46(3), 224-232. doi: 10.1176/ appi.psy.46.3.224

Instituto Mexicano del Seguro Social. (16/03/2017) Evaluación y abordaje psicooncológico en personas adultas con cáncer en tercer nivel. Ciudad de México.

Fielding, R. (2019). Developing a preventive psycho-oncology for a global context. The International Psycho-Oncology Society 2018 Sutherland Award Lecture. Psycho-Oncology. doi: 10.1002/pon.5139

Grassi, L., Watson, M., \& IPOS Federation of Psycho-Oncology Societies' coauthors. (2012). Psychosocial care in cancer: An overview of psychosocial programmes and national cancer plans of countries within the International Federation of Psycho-Oncology Societies. Psycho-Oncology, 21(10), 10271033. doi: $10.1002 /$ pon. 3154

Griner, D. \& Smith, T. B. (2006). Culturally adapted mental health intervention: A meta-analytic review. Psychotherapy: Theory, Research, Practice, Training, 43(4), 531-548. doi: 10.1037/0033-3204.43.4.531

Holland, J., Watson, M., \& Dunn, J. (2011). The IPOS new International Standard of Quality Cancer Care: Integrating the psychosocial domain into routine care. Psycho-oncology, 20(7), 677-680. doi: 10.1002/pon.1978

Krebber, A. M. H., Buffart, L. M., Kleijn, G., Riepma, I. C., De Bree, R., Leemans, C. R., ... \& Verdonck-de Leeuw, I. M. (2014). Prevalence of depression in cancer patients: A meta-analysis of diagnostic interviews and self-report instruments. Psycho-Oncology, 23(2), 121-130. doi: 10.1002/pon.3409

Krok-Schoen, J. L., Fernandez, K., Unzeitig, G. W., Rubio, G., Paskett, E. D., \& Post, D. M. (2019). Hispanic breast cancer patients' symptom experience and patientphysician communication during chemotherapy. Supportive Care in Cancer, 27(2), 697-704. doi: 10.1007/s00520-018-4375-y

Luckett, T., Goldstein, D., Butow, P. N., Gebski, V., Aldridge, L. J., McGrane, J., ... \& King, M. T. (2011). Psychological morbidity and quality of life of ethnic minority patients with cancer: A systematic review and meta-analysis. Lancet Oncology, 12(13), 1240-1248. doi: 10.1016/S1470-2045(11)70212-1

Penedo, F. J., Traeger, L., Dahn, J., Molton, I., Gonzalez, J. S., Schneiderman, N., \& Antoni, M. H. (2007). Cognitive behavioral stress management intervention improves quality of life in Spanish monolingual hispanic men treated for localized prostate cancer: Results of a randomized controlled trial. International Journal of Behavioral Medicine, 14(3), 164-172. doi: 10.1007/BF03000188

Senf, B., Fettel, J., Demmerle, C., \& Maiwurm, P. (2019). Physicians' attitudes towards psycho-oncology, perceived barriers, and psychosocial competencies: Indicators of successful implementation of adjunctive psycho-oncological care?. Psycho-oncology, 28(2), 415-422. doi: 10.1002/pon.4962

Vaccaro, L., Shaw, J., Sethi, S., Kirsten, L., Beatty, L., Mitchell, G., ... \& Turner, J. (2019) Barriers and facilitators to community-based psycho-oncology services: A qualitative study of health professionals' attitudes to the feasibility and acceptability of a shared care model. Psycho-Oncology. doi: 10.1002/pon.5165

Yanez, B., Thompson, E. H., \& Stanton, A. L. (2011). Quality of life among Latina breast cancer patients: A systematic review of the literature. Journal of Cancer Survivorship, 5(2), 191-207. doi: 10.1007/s11764-011-0171-0 